\title{
latrogenic tracheobronchial laceration: the need for surgery or the need for better studies?
}

\author{
Erich Stoelben ${ }^{1}$, Corinna Ludwig ${ }^{2}$ \\ ${ }^{1}$ Lungclinic, Hospital of Cologne, Department of Thoracic Surgery, University Witten Herdecke, Cologne, Germany; ${ }^{2}$ Thoracic Surgery, Florence- \\ Nightingale-Hospital, Dusseldorf, Germany \\ Correspondence to: Erich Stoelben, MD, PhD. Lungclinic, Hospital of Cologne, Department of Thoracic Surgery, University Witten Herdecke, 51109 \\ Cologne, Germany. Email: stoelbene@kliniken-koeln.de. \\ Provenance and Peer Review: This article was commissioned by the editorial office, fournal of Thoracic Disease. The article did not undergo external peer \\ review. \\ Comment on: Herrmann D, Volmerig J, Al-Turki A, et al. Does less surgical trauma result in better outcome in management of iatrogenic \\ tracheobronchial laceration? J Thorac Dis 2019;11:4772-81.
}

Submitted Jan 06, 2020. Accepted for publication Feb 20, 2020.

doi: $10.21037 /$ jtd.2020.03.110

View this article at: http://dx.doi.org/10.21037/jtd.2020.03.110

Surgery is dedicated to healing diseases, relieve symptoms or improve quality of life. In some cases, the effect of surgery is obvious such as prima facie evidence used in court. For example, anatomic resection of lung cancer in stage I heals most of the patients who are fit for surgery whereas many of the patients without treatment would die of disease progression (1). Almost no one would seriously plan a prospective randomized study to evaluate the low evidence-based level supporting the indication of surgery, or would you?

In contrast to this thought, the circumstances of iatrogenic tracheobronchial laceration are numerous even though it rarely happens. The comorbidities of the patient, the mechanism and extension of the tracheal injury, the impairment of ventilation caused by air-leakage into the mediastinum and the clinical presentation of the patient (cardiopulmonary instability/septic shock) lead to a wide range of possibilities how to manage the patient.

The groups at risk are female patients needing an emergency intubation. The mechanism of injury is not well investigated or defined. The level of injury in the trachea and the typical disruption of the membranous wall of the trachea plead for a mechanism where the trachea has been overstretched by overinflating the tube cuff. Therefore, injury beyond the trachea to the esophagus or mediastinal vessels is seldom. The disruption affects the mucosa and the tracheal muscle regularly. The classification of severity proposed by Giuseppe Cardillo in 2010 has not been verified (2). Furthermore, in the original publication the authors reported about a small series of 30 patients. There were 3, 24, 2 and 1 patients in the severity level I, II, IIIA and IIIB. We therefore cannot recommend the use of this classification for intubation injury nor for the description of tracheal injury after dilatation tracheotomy or endoscopic perforation of the tracheobronchial tree.

Starting with pathophysiology little is known about spontaneously healing of a tracheal rupture and how it affects the stability and function of the posterior wall of the trachea. Bronchoscopic control of extubated patients after typical lacerations shows an effective contraction of the defect by a scar which is then covered by mucosa within 14-21 days. Mediastinitis is uncommon without a source of infection. Manipulation by endotracheal stents stretches the trachea even more so the edges of the wound are far apart and the presence of a foreign body impairs the effective natural course of wound healing and could increase the risk of infection.

Indeed, successful conservative treatment was reported first by the group of Jean-François Velly from Bordeaux, France in 2000 (3) and later confirmed by others (4). The ideal patient who benefits from conservative treatment had an elective intubation, develops limited soft tissue emphysema, does not have a pneumothorax and is breathing spontaneously.

Perforation of the tracheobronchial wall during interventional bronchoscopy and endobronchial tumor 
resection by different techniques may occur (but are not published?) and is treated conservatively unless other organs like esophagus, pleura or vessels are involved. The same is applicable, if the posterior wall of the trachea is perforated under dilatational percutaneous tracheotomy.

In patients, where spontaneous breathing is impossible due to comorbidities, the tube cuff is placed below the injured part of the trachea and the medical treatment of the underlying disease, which may be life threatening by itself, is continued. Emergency surgery in these cases is accompanied by a high mortality and possibly even with intraoperative deaths, as documented by the authors and preceding publications.

Is there a place for surgery in tracheobronchial perforation as recommended by the authors?

(I) Perforation of the distal trachea with involvement of bifurcation and main bronchus are not easy to handle, if the patient is mechanically ventilated.

(II) Perforation of the trachea and rupture of the mediastinal pleura can lead to a uni- or even bilateral pneumothorax. A pleural drainage would not be effective due to the tracheopleural fistula.

(III) An intraoperative rupture of the tracheobronchial tree during esophageal or lung surgery producing a tracheo- or bronchopleural communication must be corrected surgically.

Coming back to our initial statement, the thoracic surgeon should select well the patients who might benefit from surgery or who might profit more from the advantages of an effective spontaneous tracheal wound healing to reduce the risks and mortality. Taking into consideration the low number of cases and the many-faceted clinical circumstances a multidisciplinary team should manage the patient.

Endoscopic suturing sometimes facilitated by a tracheotomy (5) and transcervical approach (6) may reduce the risk and invasiveness of the procedure in appropriate cases. Extracorporeal carbon dioxide elimination is increasingly gaining importance in respiratory failure and thoracic surgery and will find his place in the management of patients with tracheobronchial injury (7).

The paper summarizes the experience of the authors and represents the practice of a large thoracic surgery department. Simultaneously it reveals the fact that we need more prospective studies with well defined protocols including patient relevant end points.

We thank the authors for sharing their large experience on the treatment of the challenging patients with iatrogenic tracheobronchial injuries and the constructive discussion.

\section{Acknowledgements}

Funding: None.

\section{Footnote}

Conflicts of Interest: Both authors have completed the ICMJE uniform disclosure form (available at http://dx.doi. org/10.21037/jtd.2020.03.110). The authors have no conflicts of interest to declare.

Ethical Statement: The authors are accountable for all aspects of the work in ensuring that questions related to the accuracy or integrity of any part of the work are appropriately investigated and resolved.

Open Access Statement: This is an Open Access article distributed in accordance with the Creative Commons Attribution-NonCommercial-NoDerivs 4.0 International License (CC BY-NC-ND 4.0), which permits the noncommercial replication and distribution of the article with the strict proviso that no changes or edits are made and the original work is properly cited (including links to both the formal publication through the relevant DOI and the license). See: https://creativecommons.org/licenses/by-nc-nd/4.0/.

\section{References}

1. Haasbeek CJ, Palma D, Visser O, et al. Early-stage lung cancer in elderly patients: a population-based study of changes in treatment patterns and survival in the Netherlands. Ann Oncol 2012;23:2743-7.

2. Cardillo G, Carbone L, Carleo F, et al. Tracheal lacerations after endotracheal intubation: a proposed morphological classification to guide non-surgical treatment. Eur J Cardiothorac Surg 2010;37:581-7.

3. Jougon J, Ballester M, Choukroun E, et al. Conservative treatment for postintubation tracheobronchial rupture. Ann Thorac Surg 2000;69:216-20.

4. Miñambres E, Buron J, Ballesteros MA, et al. Tracheal rupture after endotracheal intubation: a literature systematic review. Eur J Cardiothorac Surg 2009;35:1056-62.

5. Welter S, Krbek T, Halder R, et al. A new technique for complete intraluminal repair of iatrogenic posterior tracheal lacerations. Interact Cardiovasc Thorac Surg 
2011;12:6-9.

6. Angelillo-Mackinlay T. Transcervical repair of distal membranous tracheal laceration. Ann Thorac Surg 1995;59:531-2.

Cite this article as: Stoelben E, Ludwig C. Iatrogenic tracheobronchial laceration: the need for surgery or the need for better studies? J Thorac Dis 2020;12(7):3475-3477. doi: 10.21037/jtd.2020.03.110
7. Sian K, McAllister B, Brady P. The use of extracorporeal membrane oxygenation therapy in the delayed surgical repair of a tracheal injury. Ann Thorac Surg 2014;97:338-40. 